\title{
THE NATURE OF THE RENAL CIRCULATORY CHANGES IN CHRONIC CONGESTIVE FAILURE AS REFLECTED BY RENAL TUBULAR MAXIMAL FUNCTIONS 1,2
}

\author{
By J. GROSSMAN, R. E. WESTON, J. P. HALPERIN, ${ }^{3}$ AND L. LEITER \\ (From the Medical Division, Montefiore Hospital, New York City)
}

(Submitted for publication June 2, 1950; accepted, July 3, 1950)

Intermittency of glomerular activity in man has not been demonstrated (1). Therefore, functional changes in the renal hemodynamics of human subjects generally have been attributed to proportional changes in the flow to all nephrons. Thus, the well-established decrease of glomerular filtration rate and renal blood flow in chronic congestive failure $(2,3)$ has been considered a result of inadequate cardiac output and secondary renal vasoconstriction, occurring without reduction in the mass of functioning tubules. Since the decrease in filtration reduces the quantity of electrolyte delivered to tubules normally adapted to handle a larger load $(4,5)$, it has been postulated that the resulting glomerulo-tubular imbalance contributes significantly to the salt and water retention of congestive failure.

Recent studies from this and other laboratories $(6,7)$ indicate, however, that despite the markedly increased renal $\mathrm{A}-\mathrm{V}$ oxygen difference, there is a significant reduction in renal oxygen consumption in chronic congestive failure. Although this could represent a diffuse depression of parenchymal metabolism, resulting from generalized renal ischemia and hypoxia, an alternative hypothesis exists. In the light of Trueta's demonstration of an intrarenal vascular shunting mechanism in other species (8), this lower oxygen consumption may reflect an intrarenal diversion of blood away from the cortex, bypassing entire nephrons and thereby diminishing the functional mass of actively metabolizing parenchyma. Such a shunting mechanism would result in a decrease in functioning tubules, proportionate to the reduced filtration, and thus would minimize the role of

\footnotetext{
1 Presented before the Association of American Physicians, Atlantic City, N. J., May 2, 1950.

2 Supported in part by grants from the National Heart Institute, U. S. Public Health Service, Campbell Products, Inc., and the Martha M. Hall Foundation.

8 Eli Lilly Research Fellow in Medicine.
}

glomerulo-tubular imbalance in the salt retention of congestive failure.

Previously, we (6) and others (7) had found, by renal vein catheterization, that renal extraction of para-aminohippurate $(\mathrm{PAH})$ in congestive failure is normal. Although some have considered such data as evidence against the existence of intrarenal shunts, this conclusion is not justified. In these earlier studies low plasma levels of PAH were employed to measure renal blood flows. Therefore, were blood shunted away from part of the kidney through juxtamedullary glomeruli and related tubules, as postulated by Trueta, these nephrons could extract the normal fraction of $\mathrm{PAH}$ until the PAH load reaching the perfused tubules exceeded that received at normal renal blood flows when the plasma PAH concentration is at the self-depression limit. Since tubular load is a function of plasma flow and plasma concentration, the greatly reduced renal plasma flow of congestive failure obviously will enhance this capacity.

Therefore, to determine whether the reduced renal hemodynamics in chronic congestive failure proportionately affects all nephrons, the following determinations were performed:

(1) Glomerular filtration rate (GFR).

(2) Renal plasma flow (RPF).

(3) Maximal tubular capacity for excreting para-aminohippurate $\left(\mathrm{Tm}_{\mathrm{PAH}}\right)$, a measure of functional tubular excretory mass.

(4) Maximum tubular capacity for reabsorbing glucose $\left(\mathrm{Tm}_{\mathrm{G}}\right)$, a measure of the number of functioning intact nephrons.

From the data obtained, it is possible to establish the nature of the renal circulatory changes in congestive failure.

\section{METHODS AND MATERIAL}

The subjects were five males and ten females with rheumatic heart disease in well-established chronic con- 
TABLE I

Clinical data on patients with rheumatic heart disease in chronic congestive failure

\begin{tabular}{|c|c|c|c|c|c|c|c|c|c|c|}
\hline \multirow{2}{*}{ Patient } & \multirow{2}{*}{ Sex } & \multirow{2}{*}{ Age } & \multirow{2}{*}{ Weight } & \multicolumn{2}{|c|}{ Circ. time } & \multirow{2}{*}{$\begin{array}{l}\text { Venous } \\
\text { Pressure }\end{array}$} & \multicolumn{4}{|c|}{ Clinical findings } \\
\hline & & & & Ether & Dech. & & Liver & Ascites & Pulm. cong. & Periph. edema \\
\hline F. B. & F & $\begin{array}{c}y r s . \\
52\end{array}$ & $\begin{array}{l}\mathrm{kgm} . \\
58.1\end{array}$ & sec. & $\begin{array}{l}\text { sec. } \\
21\end{array}$ & $\begin{array}{c}\mathrm{Cm} . \mathrm{H}_{3} \mathrm{O} \\
9\end{array}$ & $2+$ & 0 & Prev. 2+ & Prev. 2+ \\
\hline S. P. & $\mathbf{M}$ & 30 & 60.9 & 13 & 32 & 6 & 0 & 0 & Prev. 2+ & Prev. 2+ \\
\hline M. C. & F & 55 & 36.3 & 13 & 33 & 8 & $3+$ & 0 & $1+$ & Prev. $1+$ \\
\hline M. L. & F & 39 & 47.4 & 15 & 42 & 24 & $4+$ & $4+$ & Prev. 3+ & Prev. 2+ \\
\hline M. V. & $\mathbf{M}$ & 46 & 54.0 & - & - & - & 0 & 0 & $2+$ & 0 \\
\hline M. S. & $\mathbf{F}$ & 23 & $\begin{array}{l}61.1 \\
65.3\end{array}$ & 二 & $=$ & 23 & $\begin{array}{l}4+ \\
4+\end{array}$ & $\begin{array}{l}\mathbf{0} \\
\mathbf{0}\end{array}$ & Prev. ${ }_{0}^{2+}$ & $\begin{aligned} & \text { Prev. } 2+ \\
& 2+\end{aligned}$ \\
\hline G. S. & F & 42 & 47.1 & 14 & 47 & 17 & $4+$ & 0 & $1+$ & Prev. 3+ \\
\hline E. B. & $\mathbf{F}$ & 33 & $\begin{array}{l}59.0 \\
53.6\end{array}$ & 20 & 28 & $\begin{array}{l}23 \\
20\end{array}$ & $\begin{array}{l}4+ \\
4+\end{array}$ & $\begin{array}{l}4+ \\
1+\end{array}$ & $\begin{array}{l}4+ \\
4+\end{array}$ & $\begin{array}{l}3+ \\
3+\end{array}$ \\
\hline J. McM. & $\mathbf{M}$ & 33 & $\begin{array}{l}57.1 \\
56.6 \\
59.4\end{array}$ & $\frac{-}{15}$ & $\frac{34}{53}$ & $\begin{array}{l}13 \\
25 \\
27\end{array}$ & $\begin{array}{l}4+ \\
4+ \\
4+ \\
\end{array}$ & $\begin{array}{l}\mathbf{0} \\
0 \\
0\end{array}$ & $\begin{array}{l}3+ \\
3+ \\
4+\end{array}$ & $\begin{array}{l}1+ \\
1+ \\
3+ \\
\end{array}$ \\
\hline G. R. & F & 36 & $\begin{array}{l}56.8 \\
59.2\end{array}$ & $\begin{array}{l}11 \\
11\end{array}$ & $\begin{array}{l}24 \\
24\end{array}$ & $\begin{array}{r}9 \\
15\end{array}$ & $\begin{array}{l}1+ \\
3+\end{array}$ & $\begin{array}{l}\mathbf{0} \\
0\end{array}$ & $\begin{array}{l}1+ \\
2+\end{array}$ & Prev. ${ }_{0}^{1+}$ \\
\hline A. $P$. & $\mathbf{M}$ & 32 & $\begin{array}{l}65.2 \\
67.8 \\
58.8\end{array}$ & $\begin{array}{l}\overline{28} \\
17\end{array}$ & $\begin{array}{l}45 \\
55 \\
30\end{array}$ & $\begin{array}{r}19 \\
25 \\
7\end{array}$ & $\begin{array}{l}0 \\
3+ \\
0\end{array}$ & $\begin{array}{l}0 \\
0 \\
0\end{array}$ & $\begin{array}{l}0 \\
1+ \\
0\end{array}$ & $\begin{array}{l}0 \\
1+ \\
0\end{array}$ \\
\hline M. H. & F & 28 & 48.7 & 24 & 40 & 9 & 0 & 0 & Prev. 2+ & Prev. $1+$ \\
\hline J. F. & $\mathbf{M}$ & 56 & 76.2 & 20 & 48 & 20 & $4+$ & $1+$ & $2+$ & Prev. 2+ \\
\hline A. $\mathrm{McD}$. & $\mathbf{F}$ & 24 & $\begin{array}{l}55.8 \\
54.5\end{array}$ & $\begin{array}{l}16 \\
18\end{array}$ & $\begin{array}{l}22 \\
24\end{array}$ & $\begin{array}{l}23 \\
15\end{array}$ & $\begin{array}{l}3+ \\
3+\end{array}$ & $\begin{array}{l}\mathbf{0} \\
\mathbf{0}\end{array}$ & $\begin{array}{l}1+ \\
1+\end{array}$ & $\begin{array}{r}\text { Prev. } 2+ \\
1+\end{array}$ \\
\hline E. K. & F & 37 & 45.4 & - & - & - & $3+$ & $1+$ & $2+$ & 0 \\
\hline
\end{tabular}

gestive failure. Their mean age was 38 years. Although they exhibited varying degrees of edema, all retained salt and water when their sodium intake was increased. Moreover, they showed the usually accepted criteria of congestive failure-elevated venous pressure or hepato-jugular reflux, prolonged circulation times, hepatomegaly, pulmonary rales, and the usual symptoms (Table I). Most of the subjects were digitalized, and received mercurials only as indicated. Patients with a history or clinical evidence of hypertension, arteriosclerosis, or any organic renal disease were excluded from the study.

The renal studies were performed by means of the constant infusion technique of Smith and his associates (9). The patients were in the post-absorptive state, under moderate water diuresis. Urine specimens were collected at 15-30 minute intervals, by washing the catheterized bladder with sterile, distilled water and air. Blood specimens were obtained from an indwelling femoral arterial needle. Inulin, thiosulfate, and mannitol were used for the determination of GFR.4

After three or more clearance periods during which GFR and RPF were measured, appropriate solutions to maintain the plasma glucose or $\mathrm{PAH}$ concentration at suitable levels were administered. After 30 minutes of equilibration, at least four 10-15 minute Tm determinations were performed. ${ }^{5} T_{m_{P A B}}$ and $T_{m_{0}}$ determinations were carried out on separate days in all but three patients (E. K., M. V., and A. MCD.). In four patients, $T_{\mathrm{PAB}}$ measurements were repeated prior to and following the intensification of failure by the addition of salt

4 Mannitol was used in a few experiments, although it was recognized that about 10 per cent of this hexitol is reabsorbed (10).

5 During these studies, including those on one patient (E. K.) with low Tm's, the load/Tm ratios, calculated in the usual manner (9), were adequate. 
to the low $(0.4-0.6 \mathrm{gm}$.) sodium cardiac diet on which all patients were maintained.

Inulin, mannitol and PAH were determined by the usual methods (9). Prior to determination of mannitol, PAH was acetylated as suggested by Barker and Clark (11). Thiosulfate was determined by the method of Gilman, Phillips and Koelle (12), as modified by Elliott and Scott (13). True glucose was determined by the method of Nelson (14).

The higher concentrations of glucose required for $T m_{0}$ measurements because of the reduced filtration rate in cardiacs were found to interfere with the mannitol determinations, as others (15) have reported in normal subjects. Since no glucose could be detected after yeasting of the samples, the falsely high mannitol values obtained were attributed to some product(s) of glucose fermentation. Because the degree of interference, in either mannitol-free blanks or solutions containing known amounts of mannitol, was directly proportional to the glucose content of the analyzed samples, the true mannitol levels theoretically could be calculated. However, on several occasions, Tme's calculated on the basis of such corrections differed significantly from the actual Tme determined with thiosulfate or inulin clearances. Therefore, thiosulfate or inulin was employed to measure filtration rate throughout. When inulin was used, additional inulin blanks, containing the same concentrations of glucose as the diluted plasma and urine samples, also were yeasted and

TABLE II

Maximal renal tubular function in rheumatic heart disease with chronic congestive failure

\begin{tabular}{|c|c|c|c|c|c|c|c|c|}
\hline Patient & Sex & Age & Weight & G.F.R. & R.P.F. & F.F. & $\mathbf{T}_{\mathbf{M} \mathbf{P A B}}$ & $\mathbf{T}_{\mathbf{M G}_{\mathbf{G}}}$ \\
\hline F. B. & $\mathbf{F}$ & $\begin{array}{l}\text { yrs. } \\
52\end{array}$ & $\begin{array}{l}\text { kgm. } \\
58.1 \\
58.0\end{array}$ & $\begin{array}{c}\text { ml./min./ } \\
1.73 M^{2} \\
74.0 \\
71.4\end{array}$ & $\begin{array}{c}\text { ml./min./ } \\
1.73 M^{2} \\
295 \\
378\end{array}$ & $\begin{array}{l}.25 \\
.19\end{array}$ & $\begin{array}{c}\operatorname{mg.}_{1.73 M^{2}} / \min \\
\overline{90.8}\end{array}$ & $\begin{array}{c}\operatorname{mg} / \min _{1 . /} \\
1.73 \mathrm{M}^{2} \\
301 \\
-\end{array}$ \\
\hline S. P. & $\mathbf{M}$ & 30 & $\begin{array}{l}61.1 \\
60.6\end{array}$ & $\begin{array}{l}86.8 \\
92.8\end{array}$ & $\begin{array}{l}258 \\
264\end{array}$ & $\begin{array}{l}.34 \\
.35\end{array}$ & $\overline{69.1}$ & 450 \\
\hline M. C. & $\mathbf{F}$ & 55 & 36.3 & 82.7 & 272 & .30 & - & 291 \\
\hline M. L. & $\mathbf{F}$ & 39 & $\begin{array}{l}47.3 \\
47.5\end{array}$ & $\begin{array}{l}68.0 \\
66.3\end{array}$ & $\overline{270}$ & $\overline{.22}$ & $\overline{88.4}$ & $\underline{234}$ \\
\hline M. V. & $\mathbf{M}$ & 46 & 54.0 & 96.8 & 391 & .25 & 70.5 & 419 \\
\hline M. S. & $\mathbf{F}$ & 23 & $\begin{array}{l}60.6 \\
61.8 \\
65.3\end{array}$ & $\begin{array}{r}90.0 \\
109.0 \\
108.0\end{array}$ & $\begin{array}{l}386 \\
373 \\
314\end{array}$ & $\begin{array}{l}.23 \\
.29 \\
.34\end{array}$ & $\overline{64.4}$ & $\begin{array}{c}364 \\
383 \\
-\end{array}$ \\
\hline G. S. & $\mathbf{F}$ & 42 & 47.1 & 95.8 & 434 & .22 & 79.5 & - \\
\hline E. B. & $\mathbf{F}$ & 33 & $\begin{array}{l}59.0 \\
53.6\end{array}$ & $\begin{array}{l}89.4 \\
94.7\end{array}$ & $\begin{array}{l}204 \\
237\end{array}$ & $\begin{array}{l}.44 \\
.40\end{array}$ & $\begin{array}{l}78.8 \\
-\end{array}$ & $\overline{304}$ \\
\hline J. McM. & $\mathbf{M}$ & 33 & $\begin{array}{l}57.1 \\
56.6 \\
59.4\end{array}$ & $\begin{array}{r}101.0 \\
94.2 \\
111.0\end{array}$ & $\begin{array}{l}228 \\
249 \\
213\end{array}$ & $\begin{array}{l}.44 \\
.38 \\
.52\end{array}$ & $\frac{103.0}{77.8}$ & $\overline{362}$ \\
\hline G. R. & $\mathbf{F}$ & 36 & $\begin{array}{l}56.8 \\
59.2\end{array}$ & $\begin{array}{l}110.0 \\
104.0\end{array}$ & $\begin{array}{l}257 \\
199\end{array}$ & $\begin{array}{l}.43 \\
.52 \\
\end{array}$ & $\begin{array}{l}81.4 \\
84.9\end{array}$ & - \\
\hline A. $\mathbf{P}$. & $\mathbf{M}$ & 32 & $\begin{array}{l}65.3 \\
65.0 \\
67.8 \\
58.8\end{array}$ & $\begin{array}{l}91.2 \\
74.9 \\
94.0 \\
86.0\end{array}$ & $\begin{array}{l}207 \\
221 \\
197 \\
233\end{array}$ & $\begin{array}{l}.44 \\
.34 \\
.48 \\
.37\end{array}$ & $\frac{64.2}{67.6}$ & $\frac{\overline{288}}{352}$ \\
\hline M. H. & $\mathbf{F}$ & 28 & 48.7 & 90.7 & 243 & .37 & - & 322 \\
\hline J. F. & $\mathbf{M}$ & 56 & 76.0 & 59.0 & 132 & .45 & 81.4 & - \\
\hline A. McD. & $\mathbf{F}$ & 24 & $\begin{array}{l}55.8 \\
54.4\end{array}$ & $\begin{array}{l}106.0 \\
107.0\end{array}$ & $\begin{array}{l}325 \\
255\end{array}$ & $\begin{array}{l}.33 \\
.42\end{array}$ & $\begin{array}{l}77.0 \\
69.0\end{array}$ & $\overline{369}$ \\
\hline E. $\mathbf{K}$. & F & 37 & 45.4 & 76.9 & 273 & .28 & 33.5 & 189 \\
\hline Mean & & 38 & & 88.5 & 277 & .34 & 74.5 & 328 \\
\hline $\begin{array}{l}\text { Normal } \\
\text { Mean }\end{array}$ & $\begin{array}{l}\text { Males } \\
\text { Females }\end{array}$ & & & $\begin{array}{l}127.0 \\
118.0\end{array}$ & $\begin{array}{l}655 \\
600\end{array}$ & $\begin{array}{l}.19 \\
.20\end{array}$ & $\underline{77.2}$ & $\begin{array}{l}375 \\
303\end{array}$ \\
\hline
\end{tabular}


analyzed, in order to be certain that there was no interference from glucose.

Preliminary studies established that there was no effect of either glucose or thiosulfate on the determination of the other substance. However, during Tma determinations with thiosulfate, it was found advisable to administer the glucose from a separate flask and into a separate vein.

\section{RESULTS}

The pertinent data on each patient are presented in Table II.

The glomerular filtration rate (mean $=88.5 \mathrm{ml}$. per min. per $1.73 \mathrm{M}^{2} ; \sigma=14.0$ ) in these patients was reduced to 46.4 to 93.2 per cent of corresponding average normal values for the respective sexes (16). Because of the greater reduction in renal plasma flow (mean $=277 \mathrm{ml}$. per $\mathrm{min}$. per $1.73 \mathrm{M}^{2} ; \sigma=74.0$ ), which ranged from 20.2 to 72 per cent of the normal average values, the filtration fraction was increased from the normal average of $0.19-0.20$ to a mean value of 0.34 .

There was no significant relationship between the intensity of clinical signs of congestive failure, venous pressures, circulation times, etc. and the absolute value of GFR in individual patients. With intensification of failure in five patients by the addition of salt to the diet, there was an increase in filtration fraction which reflected largely the further decrease in renal plasma flow (Table II).

Tubular maximal capacity for excreting paraaminohippurate $\left(T m_{P A H}\right)$ was within normal limits in 12 of the 13 subjects (mean $=74.5 \mathrm{mg}$. per min. per $1.73 \mathrm{M}^{2} ; \sigma=14.6$ ). In one patient, E. K., who had been receiving almost daily mercurials at another hospital including an injection 20 hours before the $\mathrm{Tm}$ determinations, $\mathrm{Tm}_{\mathbf{P A H}}$ was decreased to 43.5 per cent of normal.

As indicated in Figure 1, there was no demonstrable relationship between either the GFR or RPF and $\mathrm{Tm}_{\mathrm{PAH}}$, plotted as per cent of average normal values. Because of the decrease in GFR and RPF, the ratios of GFR/T $\mathrm{m}_{\mathrm{PAH}}$ and $\mathrm{RPF} / \mathrm{Tm}_{\mathbf{P A B}}$ decreased.

There was no detectable reduction in $\mathrm{Tm}_{\mathbf{P A B}}$ in those patients who exhibited gross evidence of pulmonary congestion or peripheral edema. Moreover, when the degree of failure was intensified by adding $8 \mathrm{gm}$. of $\mathrm{NaCl}$ to the daily intake, in three patients (A. P., G. R., and A. McD.) there

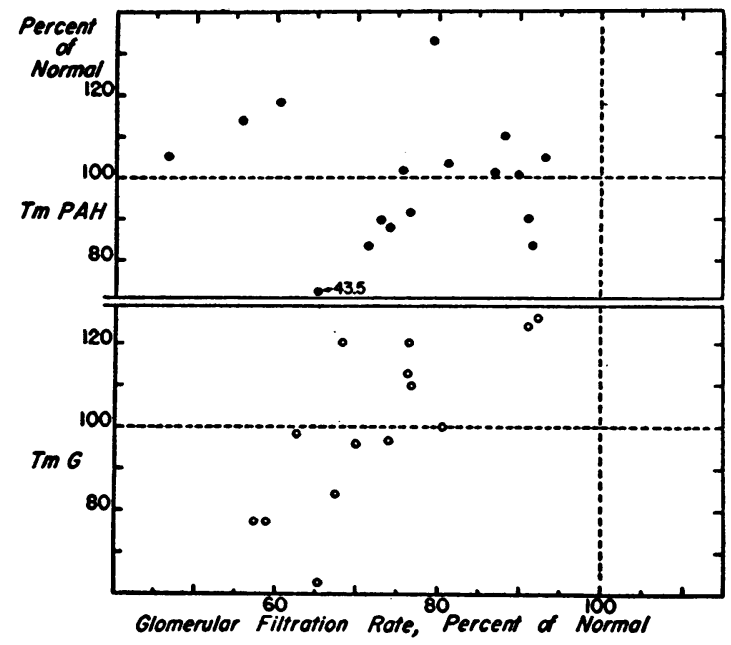

Fig. 1. The Relationship between Glomerular Filtration Rate and Tma (Open Circles) and TMpah (Closed Circles) in Congestive Failure

was no change in $\operatorname{Tm}_{\mathbf{P A B}}$, and in one (J. McM.), there was a 20 per cent decrease in the $T m_{\mathbf{P A B}}$, which remained, however, within normal limits.

Tubular maximal capacity for reabsorbing glucose $\left(T m_{\mathrm{G}}\right)$ also was within the normal limits in all patients (Mean $=328 \mathrm{mg}$. per min. per 1.73 $\mathrm{M}^{2} ; \sigma=70.8$ ), but one (E. K.), whose $T \mathrm{~m}_{\mathrm{PAH}}$ was also reduced. There was poor correlation between this tubular maximal function and GFR and RPF, when plotted as per cent of the average normal values (16) for the respective sexes (Figure 2).

Since any error in the calculated filtration rate

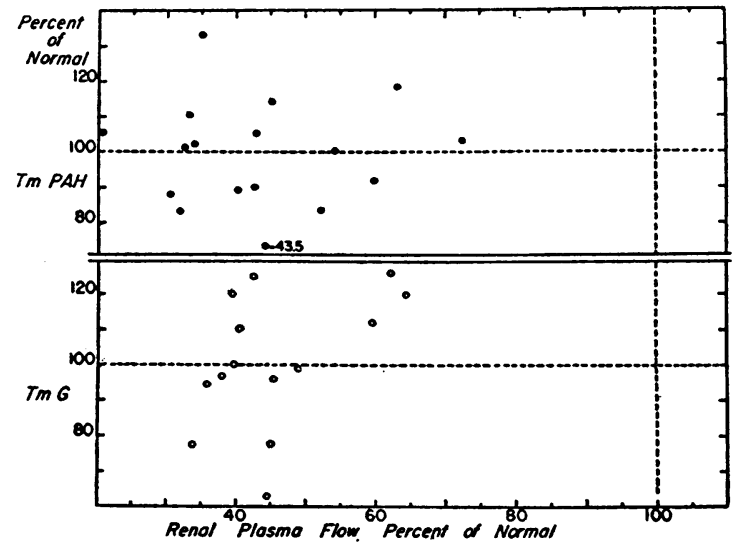

Fig. 2. The Relationship between Renal Plasma Flow and Tma (Open Circles) and Tmpah (Closed Circles) in Congestive Failure 
will produce variation in the same direction in the calculated $\mathrm{Tm}_{\mathrm{G}}$, an apparent, but spurious, correlation between the two functions may result. Furthermore this error is also proportional to the plasma concentration of glucose and will be greater in cardiac subjects in whom higher levels are necessary to achieve adequate tubular loads.

\section{DISCUSSION}

The finding of normal tubular maximal capacities for reabsorbing glucose and excreting paraaminohippurate in this series of patients in chronic congestive failure suggests that there has been a generalized reduction in blood flow to each nephron, and that at least two tubular functions have not been depressed by the marked renal ischemia and hypoxia. Previously, Landowne, Alving, and Adams (17) had found normal diodrast Tm's in two patients in severe congestive failure due to chronic constrictive pericarditis.

Others recently have reported that there may be a reduction in $\mathrm{Tm}_{\mathbf{P A B}}$ in congestive failure. Earle and his associates (18) observed that $T m_{\mathbf{P A B}}$ was reduced in two edematous patients in severe congestive failure, but returned to normal after treatment had been started and edema decreased. Heller and Jacobson (19) found that the average $\mathrm{Tm}_{\mathbf{P A B}}$ was normal in partially compensated or edema-free patients in chronic congestive failure, despite the reduction in GFR and RPF. In contrast, in eight patients exhibiting peripheral edema or rales, with elevated venous pressures and more severely reduced RPF's, the average $\mathrm{Tm}_{\mathrm{PAH}}$ was reduced. However, review of their data reveals that five of the eight severely decompensated patients were over 55 years of age, so that renal arteriosclerosis might have contributed to the reduction in $\mathrm{Tm}_{\mathbf{P A H}}$. Moreover, in the two patients in whom Tm $_{\mathbf{P A B}}$ 's were measured before and after treatment, the observed increase in $T_{m_{\mathbf{P A}}}$ after the disappearance of edema was associated with an apparent decrease in GFR. Such a measured fall, if due to technical errors alone, would result in a higher calculated $\operatorname{Tm}_{\mathbf{P A H}}$. It is also conceivable that in severely decompensated patients a marked reduction in RPF may occur during the stress of $\mathrm{Tm}_{\mathbf{P A B}}$ determination and reduce the tubular load below the required level, thereby lowering the apparent $\mathrm{Tm}$. Simultaneous right renal vein catheterization, with determina- tion of "true" RPF by the Fick method, is necessary to evaluate this point.

Similarly, Hilden's '(20) group of six patients included four patients with arteriosclerotic heart disease, with a fairly proportionate reduction in GFR and $T m_{D}$. Such findings would be anticipated in renal arteriosclerosis where various functional components of the nephrons tend to "drop out" together (21). It is noteworthy that his two younger patients with luetic heart disease had normal $\mathrm{Tm}_{\mathbf{D}}$ 's.

In the present series of severely decompensated but younger patients, presumably free of organic renal disease, there was no relationship between $\operatorname{Tm}_{\mathbf{P A B}}$ and the reduced renal circulation. Although this finding probably excludes the diversion of blood from any significant number of tubules, the possibility remains that the slower blood flow in chronic congestive failure may permit more time for the excretion of $\mathrm{PAH}$ or diffusion of $\mathrm{PAH}$ to otherwise bypassed tubules, thereby maintaining the $\mathrm{Tm}$ at normal levels. However, in other diseases leading to impaired renal hemodynamics, the $\mathrm{Tm}_{\mathbf{P A B}}$ tends to be reduced early and significantly $(9,21)$.

More important, the glucose $\mathrm{Tm}$, which is a measure of the functional integrity of both glomeruli and their attached tubules-or of the number of functioning whole nephrons-is normal in the present series of patients. If, for example, the reduced GFR in congestive failure were due to the absence of filtration in some glomeruli due to intrarenal redistribution of blood, a corresponding reduction in $\mathrm{Tm}_{\mathrm{G}}$ would result. Similarly, since each tubule can receive the glucose it reabsorbs only from the attached glomerulus, any functional exclusion of tubules also would depress the $\mathrm{Tm}_{\mathbf{G}}$. The normal $\mathrm{Tm}_{\mathrm{G}}$ encountered, therefore, is irrefutable evidence against any extensive intrarenal shunting mechanism.

It is possible that the very severe, persistent renal ischemia and hypoxia present in intractable congestive failure may lead ultimately to parenchymal metabolic depression. Under these circumstances, $\mathrm{Tm}_{\mathbf{P A H}}$ or $\mathrm{Tm}_{\mathrm{G}}$ conceivably might be reduced. ${ }^{\circ}$ However, there was no such depres-

- At this stage of so markedly reduced GFR and RPF, it is highly questionable whether plasma levels of PAH and glucose adequate for $\mathrm{Tm}$ measurements can be achieved safely. Moreover, the deleterious hemodynamic 
sion in the present series of patients in classical congestive failure, many of whom accumulated salt and water even on a low salt cardiac diet.

The renal circulatory abnormality in chronic congestive failure evidently consists of generalized renal ischemia with decrease in filtration in the glomerulus of each nephron but without reduction in the tubular mass perfused. Moreover, the finding of normal $\mathrm{Tm}_{\mathrm{G}}$ 's and $\mathrm{Tm}_{\mathbf{P} \mathbf{A B}}$ 's establishes the fact that at least two functions of the tubule are not impaired by the renal ischemia and hypoxia. Thus, there is a functional glomerulotubular imbalance which may greatly influence renal excretion of salt and water (4).

Recently, Selkurt, Hall and Spencer (22), and Pitts and Duggan (23), have demonstrated in dogs that acutely decreasing the filtration rate by 25 to 50 per cent results in the virtual disappearance of sodium from the urine. Regardless of whether one accepts or rejects the existence of a distal tubule Tm for sodium (4), these data suggest that a moderate reduction infiltration rate without change in tubular function can result in salt and water retention. Although the renal mechanism for excreting sodium in the dog may differ from that in man (24), this pattern of renal dysfunction, per se, could furnish a simple explanation for the more complete tubular reabsorption of sodium occurring in congestive failure and other conditions in which glomerular filtration is diminished more than is tubular function $(5,21,25)$.

It should be re-emphasized, however, that one of the body's responses to the inadequate output of the failing heart is to conserve salt and water $(25,26)$. That not one but several mechanisms probably are activated for this purpose is not surprising. Many factors-excessive accumulation of anti-diuretic substances, adrenal cortical steroids or hepatic VDM, increased renal or systemic venous pressure, exercise, reduced renal blood flow, etc. $(6,25,27-32)$-may promote salt and water retention in congestive failure. However, whenever the filtration rate is reduced without arteriosclerotic or hypertensive renal tubular involvement, as in younger patients in chronic congestive failure, the influence of the resulting

effects of such procedures may obviate the significance of results obtained. glomerulo-tubular imbalance on salt and water excretion should not be underestimated.

\section{SUMMARY AND CONCLUSIONS}

1. In a series of patients in well-established congestive heart failure, with characteristically reduced glomerular filtration rates and renal plasma flows, the maximal tubular capacities for the excretion of para-aminohippurate and the reabsorption of glucose were normal.

2. These findings exclude the possibility of any significant intrarenal redistribution of blood.

3. The significance of the resulting glomerulotubular imbalance in relation to the retention of sodium and water in chronic congestive failure, uncomplicated by organic renal disease, is discussed.

\section{ACKNOWLEDGMENTS}

The authors wish to express their gratitude to $\mathrm{Mr}$. Morris Wolfman, Mrs. Lila Wolfman, and Mrs. Madie Ross for their technical assistance, and to Doctors D. J. W. Escher and T. D. Ullmann for their aid in some of the studies.

\section{BIBLIOGRAPHY}

1. Smith, H. W., Lectures on the Kidney. University Extension Division, University of Kansas, Lawrence, Kansas, 1943.

2. Merrill, A. J., Edema and decreased renal blood flow in patients with chronic congestive heart failure: evidence of "forward failure" as the primary cause of edema. J. Clin. Invest., 1946, 25, 389.

3. Mokotoff, R., Ross, G., and Leiter, L., Renal plasma flow and sodium reabsorption and excretion in congestive heart failure. J. Clin. Invest., 1948, 27, 1.

4. Wesson, L. G., Jr., Anslow, W. P., Jr., and Smith, H. W., The excretion of strong electrolytes. Bull. New York Acad. Med., 1948, 24, 586.

5. Weston, R. E., Hellman, L., Escher, D. J. W., Edelman, I. S., Grossman, J., and Leiter, L., Studies on the influence of the low sodium cardiac diet and the Kempner regimen on renal hemodynamics and electrolyte excretion in hypertensive subjects. J. Clin. Invest., 1950, 29, 639.

6. Edelman, I. S., Zweifach, B. W., Escher, D. J. W., Grossman, J., Mokotoff, R., Weston, R. E., Leiter, L., and Shorr, E., Studies on VEM and VDM in blood in relation to renal hemodynamics and renal oxygen extraction in chronic congestive heart failure. J. Clin. Invest., 1950, 29, 925.

7. Stead, E. A., Jr., Myers, J. D., Scheinberg, P., Cargill, W. H., Hickam, J. B., and Levitan, B. A., 
Studies of cardiac output and of blood flow and metabolism of splanchnic area, brain, and kidney. Tr. A. Am. Physicians, 1950, in press.

8. Trueta, J., Barclay, A. E., Daniel, P. M., Franklin, K. J., and Prichard, M. M. L., Studies of the Renal Circulation. C. C. Thomas, Springfield, Ill., 1947.

9. Goldring, W., and Chasis, H., Hypertension and Hypertensive Disease. The Commonwealth Fund, New York, 1944.

10. Berger, E. Y., Farber, S. J., and Earle, D. P., Jr., Renal excretion of mannitol. Proc. Soc. Exper. Biol. \& Med., 1947, 66, 62.

11. Barker, H. G., and Clark, J. K., Effect of para-aminohippurate on mannitol determinations by the periodate-iodide-thiosulfate method. Proc. Soc. Exper. Biol. \& Med., 1947, 64, 120.

12. Gilman, A., Phillips, F. S., and Koelle, E. S., The renal clearance of thiosulfate with observations on its volume distribution. Am. J. Physiol., 1946, 146, 348.

13. Elliott, S. R., II, and Scott, H. W., Jr., Effect of paraaminohippurate on sodium thiosulfate determinations in renal clearance studies. Bull. Johns Hopkins Hosp., 1948, 83, 213.

14. Nelson, N., A photometric adaptation of the Somogyi method for the determination of glucose. J. Biol. Chem., 1944, 153, 375.

15. Kendrick, A. B., Swisher, W. P., and Forrest, R. A., Effects of glucose fermentation products on determination of mannitol by periodate titrimetric method. Proc. Soc. Exper. Biol. \& Med., 1949, 70, 677.

16. Smith, H. W., The Kidney Structure and Function in Health and Disease. Oxford Univ. Press, New York, in press.

17. Landowne, M., Alving, A. S., and Adams, W., Renal and total circulation in two cases of constrictive pericarditis. J. Clin. Invest., 1942, 21, 626.

18. Earle, D. P., Jr., Farber, S. J., Alexander, J. D., and Eichna, L. W., Effect of treatment on renal functions and electrolyte excretion in congestive heart failure. J. Clin. Invest., 1949, 28, 778.

19. Heller, B. I., and Jacobson, W. E., Renal hemodynamics in heart disease. Am. Heart J., 1950, 39, 188.
20. Hilden, T., Glomerular filtration rate and maximal tubular excretory capacity in congestive heart failure. Scandinav. J. Clin. \& Lab. Invest., 1949, 1, 305.

21. Earle, D. P., Jr., Renal function tests in the diagnosis of glomerular and tubular disease. Bull. New York Acad. Med., 1950, 26, 47.

22. Selkurt, E. E., Hall, P. W., and Spencer, M. P., Influence of graded arterial pressure decrement on renal clearance of creatinine, para-aminohippurate and sodium. Am. J. Physiol., 1949, 159, 369.

23. Pitts, R. F., and Duggan, J. J., Studies on diuretics. II. The relationship between glomerular filtration rate, proximal tubular absorption of sodium and diuretic efficacy of mercurials. J. Clin. Invest., 1950, 29, 372.

24. Ladd, M., and Raisz, L. G., The response of the normal dog to dietary sodium chloride. Am. J. Physiol., 1949, 159, 149.

25. Weston, R. E., Grossman, J., Escher, D. J. W., Mokotoff, R., and Leiter, L., Pathogenesis and treatment of salt and water retention in congestive failure. Med. Clin. N. America, 1950, 34, 615.

26. Dock, W., Physiological problems in the treatment of heart disease. J. Mt. Sinai Hosp., 1947, 13, 310.

27. Parrish, A. E., The bioassay of adrenal corticoids in the urine of patients with congestive failure. J. Clin. Invest., 1949, 28, 45.

28. Blake, W. D., Wégria, R., Keating, R. P., and Ward, $H$. $P$., The effect of increased renal venous pressure on renal function. Am. J. Physiol., 1949, 157, 1.

29. Sinclair-Smith, B., Kattus, A. A., Genest, J., and Newman, E. V., The renal mechanism of electrolyte excretion and metabolic balances of electrolytes and nitrogen in congestive heart failure; the effects of exercise, rest and aminophyllin. Bull. Johns Hopkins Hosp., 1949, 84, 369.

30. Bercu, B. A., Rokaw, S. N., and Massie, E., An antidiuretic substance in the urine of patients with cardiac failure. Proc. Am. Heart Assoc., 1949, 21.

31. Landis, E. M., and Hortenstine, J. C., Functional significance of venous blood pressure. Physiol. Rev., 1950, 30, 1.

32. Elkinton, J. R., Crosby, A. P., Jr., Barker, H. G., and Clark, J. K., Alterations in renal hemodynamics and excretion of electrolytes. Federation Proc., $1950,9,37$. 